\title{
Reinforced Concrete Sewer Pipes used for Jacking Construction of Experimental Research and Finite Element Analysis
}

\author{
Yan-Min YANG, Run-Tao ZHANG, Bo QU \\ School of Civil Engineering, Jilin Jianzhu University, Changchun 130118 \\ yymlyq@qq.com
}

\begin{abstract}
Keywords: Jacking Construction Method, Reinforced Concrete Sewer Pipes, External Pressure Load, Finite Element.
\end{abstract}

\begin{abstract}
This paper reinforced jacking construction method, which used reinforced concrete sewer pipes to conduct the external pressure load test, and the cracking load and the failure load of reinforced concrete sewer pipes were tested, and its local and overall deformation under different load levels. At the same time, we conducted the nonlinear compute of reinforced concrete sewer pipes by the finite element analysis software ABAQUS, theoretical simulation and test results were contrasted analysis, and jacking construction method, which used reinforced concrete sewer pipes, was comprehened evaluation in construction quality, mechanical behavior and failure mode, which can provide theoretical basis for practical engineering application.
\end{abstract}

\section{Introduction}

With the rapid development of urban construction,lage diameter( $\mathrm{DN} \geq 2000)$ drains as the city drainage pipeline to improve drainage status measures being used more and more ${ }^{[1]}$.Jacking construction method is one of the construction technology of reinforced concrete draingepipe trenchless pavement,because of jacking in road and blowing the buildings,can guarantee the smooth road and nomal use of buildings,but also has a shoter pipeline cycle, applicable to rail,road and difficult or not trench excavation underground pipeline construction ${ }^{[2]}$. The random sampling of large diameter pipe jacking reinforced concrete drainage pipe,applied to river emergency flood control engineering,pipe jacking 868 meters in length(909 meters upon completion).To avoid drainage construction,installation and use of crack and other problem, for sampling the finished tube external pressure loading test and finite element analysis, a comprehensive assessment of jacking method with the construction quality of reinforced concrete pipes, mechanical properties, damage morphology, as assessed with reference to quality of the finished pipe to meet the needs of practical engineering.

\section{Specimen Overview}

Test reinforced concrete pipes for grade III,Modle:DRCP2200*2500mm,inner diameter of 2.2m,pipe wall thickness $220 \mathrm{~mm}$,length $2.5 \mathrm{~m}$. With double steel skeleton inside, longitudinalreinforvedment for prestressed concrete steel bar $\Phi 10$,inner and outer sides of $24, \mathrm{fy}=1420 \mathrm{~N} / \mathrm{mm}^{2}$. .Ring stiffened double $\Phi 8$ HPB235spiral stirrups, $\mathrm{fy}=505 \mathrm{~N} / \mathrm{mm}^{2}, \mathrm{ft}=345 \mathrm{~N} / \mathrm{mm}^{2}$. Concrete strength design value C50(measured value C60), the test age for 50d,steam concrete curing,drainage pipe with vertical core mould vibration molding.

\section{External Pressure Loading Test}

\section{Test Design}

Loading test for reinforced concrete pipe with "three-point method",load test external pressure loading device shown in Figure 1. At the midpoint of the specimen bearing steel beams are applied load wiring, in order to ensure uniform load, a rubber pad between the steel beam and the specimen, supporting axis beam and bolster the next two specimens below parallel. During the test application crack width crack width gauge readings, crack width measurement in Figure 2.Measuring radial deformation of the horizontal and vertical directions were arranged 8 displacement point measuring 
point, to eliminate the impact of eccentricity, displacement in each direction takes the average of two displacement meter, the displacement of the measuring point by the four finishing averaged layout shown in Figure 3.In the medial and lateral horizontal pipe and vertical direction along the tube length of 2 column layout strain changes of strain gauge measuring cracking load and all levels of loading, strainmeasuring point layout is shown in Figure 4.

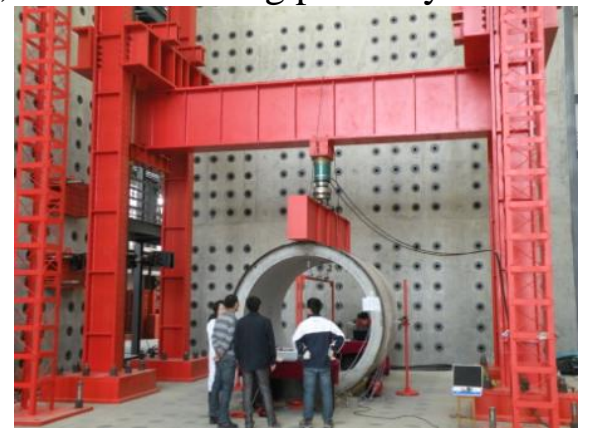

Fig.1 Test load figure

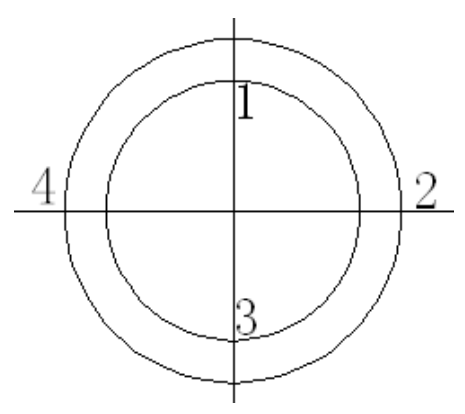

Fig.3 Displacement measuring points

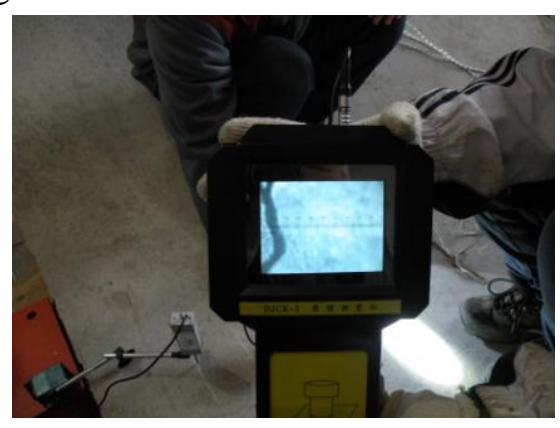

Fig.2 Crack width measurement

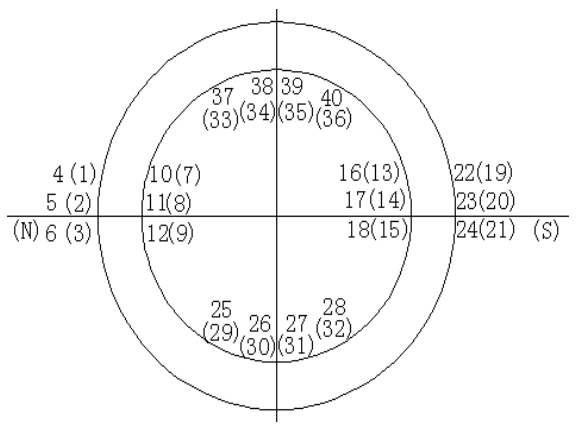

Fig.4 train measuring points

\section{Analysis of Test Results}

(1) When the drainage according to three-point test method, in order to meet functional requirements of the use of drainage, specifications ${ }^{[3]-[5]}$ to expand the width of the crack pipe has a certain limit, crack width can reach $0.2 \mathrm{~mm}$ when the specified load. Cracking load is applied in accordance with the maximum range to meet the conditions determined by the calculation, the calculation takes into account the long-term use of state transformation between load and test the role of the state between the short-term loads, failure load and generally cracking load of 1.5 times ${ }^{[6]}$, III load crack pipe and failure load specification allows values and test results are shown in Table 1.it is shown that the sampling tube of the external load of the measured values are higher, indicating that external pressure loading test to meet the design requirements.

Tab. 1 external pressure load testing result

\begin{tabular}{c|c|c|c|c|c}
\hline \multirow{2}{*}{ Project } & \multirow{2}{*}{$\begin{array}{c}\text { Cracking } \\
\text { load }\end{array}$} & \multicolumn{2}{|c|}{ Crack load } & \multicolumn{2}{c}{ Failure load } \\
\cline { 3 - 6 } & & Specification & Measured & & \\
\hline Concentration (KN) & 353 & 497.5 & 498.8 & $\begin{array}{c}\text { Concentration } \\
(\mathrm{KN})\end{array}$ & 353 \\
\hline Line load (KN/m) & 141.2 & 199 & 199.52 & $\begin{array}{c}\text { Line load } \\
(\mathrm{KN} / \mathrm{m})\end{array}$ & 141.2 \\
\hline
\end{tabular}

(2) Load - displacement curve shown in Figure 5.The figure shows, before cracking load, displacement of the specimen increased with increasing load,the load - displacement curve is linear, when the load reaches $353 \mathrm{KN}$,measuring point a crack. After cracking load,the slope of the curve decreases, the stiffness continuously decreased, when the load reaches $615.25 \mathrm{KN}$, a sharp increase in 
the displacement of the measuring point 1, but the measuring point 2 and measuring point 4 compare with the displacement of the measuring point 1 increases more slowly, which is mainly due to the helical cuff tendons significantly increased resistance to deformation of concrete, and a measuring point 1 at loading point cause large deformation. The external force, drainage radial deformation occurs in the vertical direction is greater, the maximum vertical displacement of $9.83 \mathrm{~mm}$, measuring point 2 , due to the position of the measuring point 4 symmetric load - displacement curve was close to the maximum horizontal displacement of $6.21 \mathrm{~mm}$, measured point 3 due to the specimen at the bottom of the two support beams, resulting in a smaller vertical displacement produced.

(3) Load - strain curve shown in Figure 6.The figure shows that, in a symmetrical position on both sides of the horizontal tube (measuring points 1-24), the load- strain curve closer, indicating drainage vibrated evenly better quality.Bottom of the tube measuring points 25-32 after cracking load performance characteristics of the measuring point adjacent to the strain plummeted across the crack strain measuring point surge, and. The top surface of the tube loading area, measuring points 35 first crack and quit work immediately,while the measuring point 38 showed good ductility, the maximum tensile strain near $8000 \mu \varepsilon$.

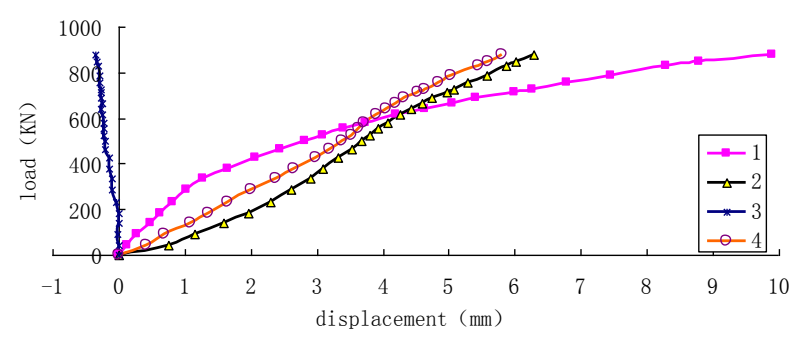

Fig.5 Load - displacement curve

(4) Crack distribution shown in Figure 7.The loading process, the top and bottom inner walls of the test piece is almost the same time cracking, and cracks in the outer wall of the first side surface, the width of the top of the inner wall cracks develop faster than the bottom, in the vicinity of the axis of the specimen a significant main crack. Opposite side wall cracking late, cracks appear more widely distributed, the slow development of cracks, wall side found no cracks . When loaded to failure load occurs the tube mouth parts to crack along the wall of the ring, accompanied by the sound burst, indicating the occurrence of slip between concrete and rebar, causing the specimen to reach the ultimate bearing capacity.
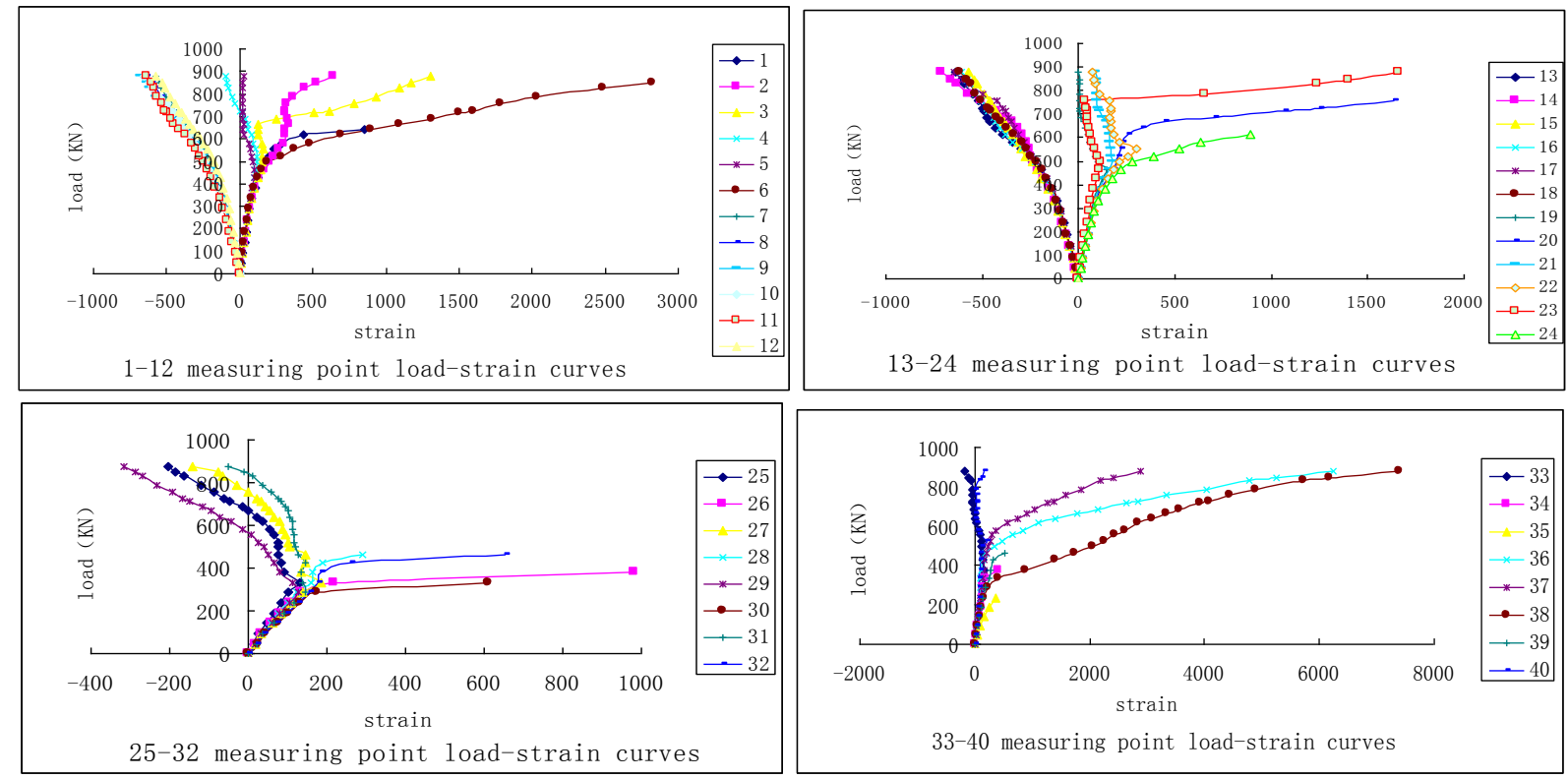

Fig.6 Each measuring point load - strain curves 


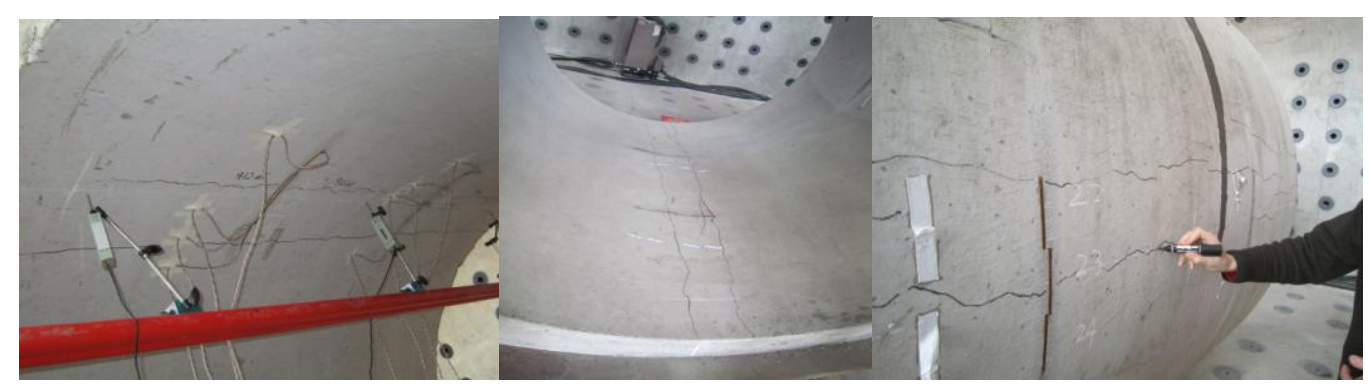

Fig.7 Crack distribution shown

\section{Finite Element Analysis}

\section{Finite Element Calculation}

Using ABAQUS finite element analysis software for sewer nonlinear finite element analysis of concrete using three-dimensional eight-node linear reduced integration unit (C3D8R), reinforced two nodes using three-dimensional space truss elements (T3D2), were separate modeling. Rebar uses embedded technology embedded in concrete, taking into account the convergence of computing, rebar and concrete cells unit a common node. Concrete stress - strain field calculation damage variable is introduced, with damage constitutive equations for concrete finite element analysis is more reasonable and accurate. Concrete constitutive damage variable based on "design of concrete structures" GB50010-2010 calculations. To ensure the accuracy of the simulation analysis, based on the test report data to determine the size of the model,material parameters, the finite element model of this paper to do the following simplification: independent of the circular stirrup instead of spiral stirrup, stirrup spacing unchanged; not consider changes in the loading surface of the tube body during the loading process, the set is loaded wide $100 \mathrm{~mm}$. Drainage model from cracking load $199 \mathrm{KN} / \mathrm{m}$ to failure load $299 \mathrm{KN} / \mathrm{m}$ of force and deformation analysis results shown in Figure 8.

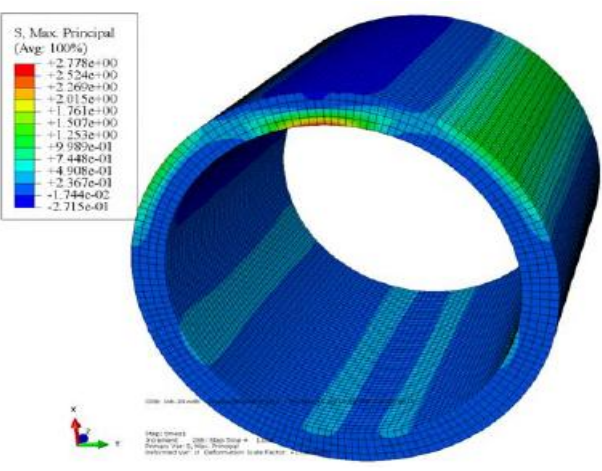

The maximum principal stress of concrete on cracking load

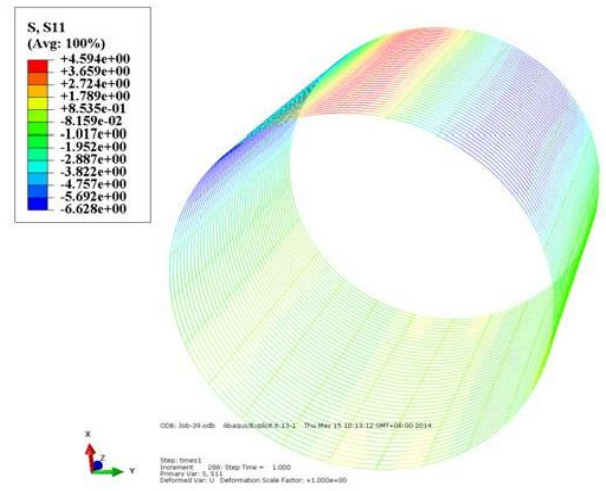

The internal stirrups direction stress along the pipe diameter on cracking load

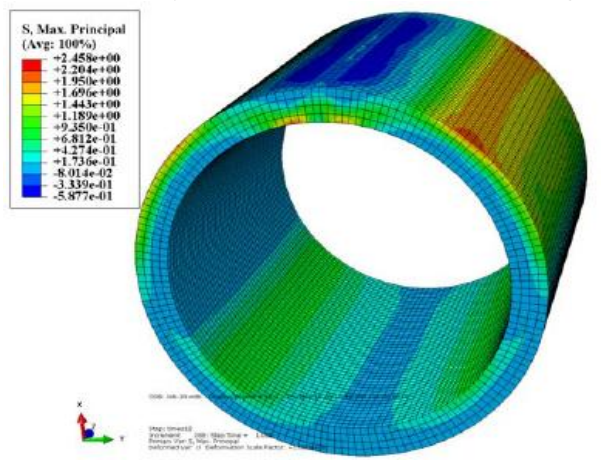

The maximum principal stress of concrete on failure load

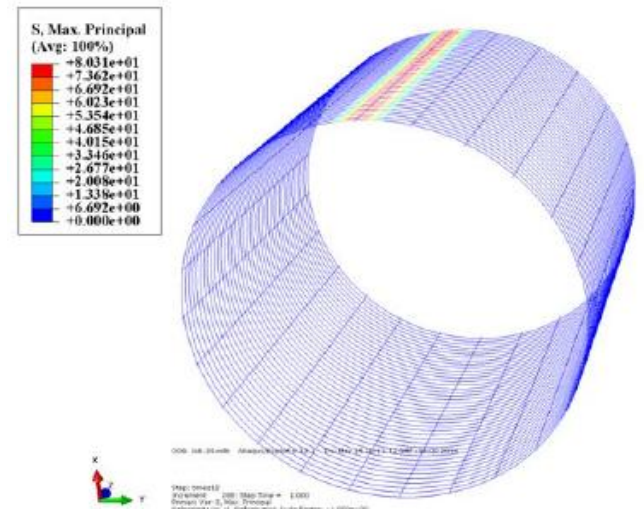

The internal stirrups direction stress along the pipe diameter on failure load 


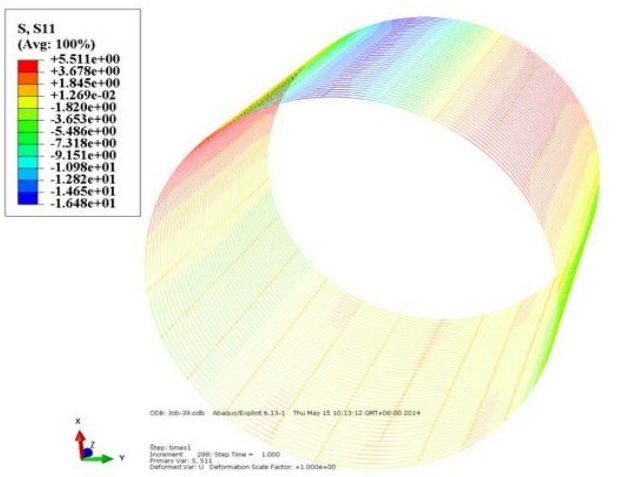

The lateral stirrups direction stress along the pipe diameter on cracking load

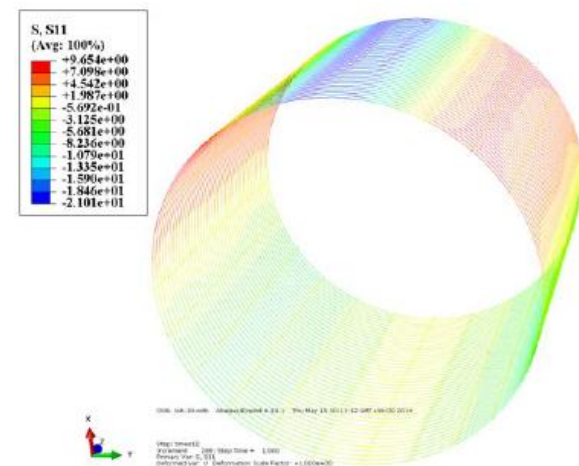

The lateral stirrups direction stress along the pipe diameter on failure load

Fig.8 The finite element analysis results on cracking load and failure load

\section{Finite Element Analysis}

Through simulationresults that: when the load is loaded to crack load $(199 \mathrm{KN} / \mathrm{m})$, the maximum principal stress of concrete is $2.77 \mathrm{MPa}$, the inside of the pipe diameter direction stirrup maximum tensile stress is $4.59 \mathrm{MPa}$, the outer diameter of the hoop direction along the tube the maximum tensile stress is $5.51 \mathrm{MPa}$; when the load is loaded to failure load $(299 \mathrm{KN} / \mathrm{m})$, the maximum principal stress of concrete dropped to $2.48 \mathrm{MPa}$, the maximum principal stress inside of stirrups is $80.3 \mathrm{MPa}$, stirrups along the outer tube diameter direction The maximum tensile stress is $9.65 \mathrm{MPa}$. Simulation results show that, with the increase of external load of concrete due to cracking and soften the inside stirrup stirrup relative lateral play a greater role in the tension and stress in the crack loads when the outer diameter of the stirrups along the direction of the tube 2 times for the destruction of loads. Stirrup force is always in the elastic stage, to ensure that the drainage in reinforced concrete prior to the destruction of ductility design purposes.

\section{Summary}

(1) Compared with the test results by the finite element simulation analysis, the loads of the two stress state distribution is consistent, tension and compression stress distribution is consistent with the theoretical calculation.

(2) The test and finite element calculation result shows that the double spiral stirrups on internal concrete not only provides uniform constraint function, at the same time can effectively improve the resistance to deformation ability of drainage pipe.

(3) Standard pipe culvert external pressure load requirement of the test load shall not be lower than design, sampling fracture load measured as the standard value of 1.09 times, breaking load measured as the standard value of 1.17 times, show that the drain design according to the existing specifications meet III level pipe outside the pressure of the load requirements, and has a certain safety stock.

\section{References}

[1] guowei, Chen bo, Wu Jidong. New technology during the construction of large diameter reinforced concrete drainage pipe - half slot pipe jacking construction technology is introduced [J]. Water supply and drainage, 2012 (12) : 100-103.

[2] GaoLizhi. The discussion of construction technology about the trenchless ground lays reinforced concrete drainage pipes[J] Heilongjiang Science and Technology Information,2010 (15): 202.

[3] People's Republic of China building materials industry standards.Jacking construction method with reinforced concrete pipes (JC/T 640-2011) [S], and the People's Republic of China Ministry of Information Industry. 
[4] People's Republic of China national standard.Concrete and reinforced concrete pipes test method (GB/T 16752-2006) [S],China National Standardization Management Committee.

[5] People's Republic of China building materials industry standard.Concrete and reinforced concrete pipes (GB/11836-2009) [S],China National Standardization Management Committee.

[6] Shenlihua, Yuhongfang. <The concrete and reinforced concrete drain pipe> national standards compiled introduction [J].Concrete and cement products, (2): 2009-31. 